UCRL-CR-134532

S/C-B304321

\title{
Surface Dynamics During Environmental Degradation of Crystal Surfaces
}

\author{
I. Smolsky
}

April 30, 1999

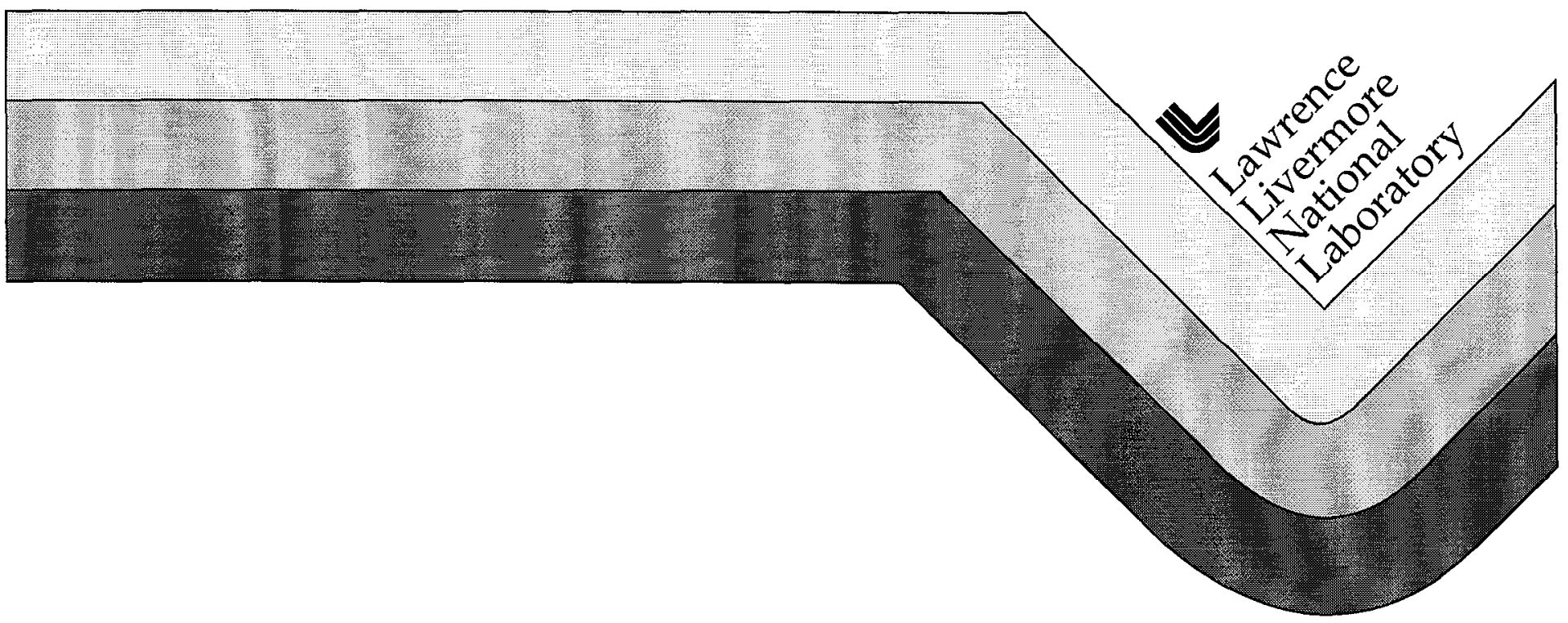




\section{DISCLAIMER}

This document was prepared as an account of work sponsored by an agency of the United States Government. Neither the United States Government nor the University of California nor any of their employees, makes any warranty, express or implied, or assumes any legal liability or responsibility for the accuracy, completeness, or usefulness of any informalion, apparalus, product, or process disclosed, or represents that its use would not infringe privately owned rights. Reference herein to any specific commercial product, process, or service by trade name, trademark, manufacturer, or otherwise, does not necessarily constitute or imply its endorsement, recommendation, or favoring by the United States Government or the University of California. The views and opinions of authors expressed herein do not necessarily state or reflect those of the United States Government or the University of California, and shall not be used for advertising or product endorsement purposes.

Work performed under the auspices of the U.S. Department of Energy by Lawrence Livermore National Laboratory under Contract W-7405-ENG-48. 
MATERIAL SUPPORT AGREEMENT NUMBER B304321

between

THE REGENTS OF THE UNIVERSITY OF CALIFORNIA

and

INSTITUTE OF CRYSTALLOGRAPHY

ACADEMY OF SCIENCES OF RUSSIA

PROJECT 3

THE FINAL REPORT

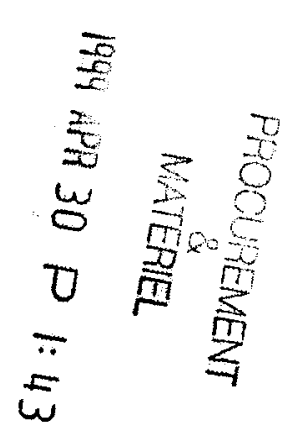




\section{INTRODUCTION}

The Final Report describes rsults of further investigation of nature of vicinal sectorality in KDP crystals.

Part I contains data of quantitative estimation of distinctions between the lattice parameters in the neighbour growth sectors and vicinal sectors of some rapidly grown KDP and DKDP crystals. It demonstrates opportunities of the plane wave $\mathrm{X}$-ray topography for quantitative characterization of crystals grown in known conditions.

Part II gives description of some mechanisms of striations formation in which the vicinal sectorality takes an important part.

\section{QUANTITATIVE ANALYSIS OF DISTORTIONS IN CRYSTALS NEAR THE BOUNDARIES OF DIFFERENT KINDS}

1). Crystal KDP LLNL \#125 (See also the Third Progress Report). It was found that the lattice parameters of the dipyramidal growth sectors are bigger than lattice parameters of the prism growth sectors in this crystal. The double crystal topographs Figure 1.1 show the central part of the z-cut of the crystal (sample 125-I). The central square is built by the dipyramid sectors of the crystal. It is surrounded by the material of the prism growth sectors. Synthesized images of the lattice parameter and small rotations changes show that the difference in the lattice parameters between dipyramid and prism sectors $\Delta c=7 \cdot 10^{-6} \AA$. There is no rotations of each growth sector relatively to others at least in three of four directions shown in the topographs. Only sectorial boundaries show some enhanced contrast related with relaxation of stresses at the smple surface. It means that there are conditions which can provide growth of crystal with some equal lattice parameters in the prism and dipyramid growth sectors and hence diminish distortions related with crystal sectoral structure.

Crystal KDP LLNL \#133, The sample 133-III (See also the Third Progress Report, Fig. 2.6). The double crystal topographs Fig. 1.2 show a part of the sample with striations formed as a result of competiton of different sources of growth steps. These striations separate relatively homogeneous parts of crystal marked by numbers $1-4$. The boundary between parts 1 and 2 is a sectoral boundary between prismatic (1) and dipyramidal (2) growth sectors. Growth bands (striations) between the other layers are evidently intervicinal boundaries. They have black and white contrast in turn. The changes of lattice parameter a and misorientations between these layers (vicinal sectors) are given in the Table 1. These measurements show that the difference in the lattice parameters as well small rotations between the vicinal sectors is relatively small. Only images of the intervicinal boundaries have some enhanced contrast related with the surface relaxation. 
$\mathrm{X}$-ray topographs of crystal KDP LLNL \#8C (Fig. 1.3) show deformations in the vicinity of intervicinal boundary in the plane of the growing face (101). The intervicinal boundary is vertical on this topographs and zig-zag lines are steps formed as a result of etching during preparation of sample for $\mathrm{x}$-ray topography. Nevertheless it is possible to see that growth steps on the left of the intervicinal boundary are almost horisontal and the growth steps on the right of the boundary are inclined at angle approximately $45^{\circ}$ to the boundary. As a result the crystal has a step-like change of the lattice parameter just at the intervicinal boundary $\Delta \mathrm{a}=3.1 \cdot 10^{-5} \AA$. It is interesting that there is not rotations at the boundary of this kind.

2). Analysis of crystal lattice distortions in the growth sectors of prismatic faces is the matter of special interest because only rapidly grown crystals have prism growth sectors of significant volumc. Fig. 1.4 shows a series of plane wave $\mathrm{x}$-ray topographs of part of prism face of DKDP crystal grown with the average rate $12 \mathrm{~mm} /$ day along Z-axis (K7-97). The topographs show the part of the crystal face containing a dislocation bunch oriented normally to the crystal surface and formed a vicinal hillock during crystal growth in the right part of the images. The vicinal hillock has four vicinal sectors and twofold symmetry in accordance with the crystal symmetry. The lattice parameters difference and small rotations are small enough because the growth steps in the opposite vicinal sectors are of the same type and orientation.

Slightly different result we can obtain if to analyse distortions in the prism growth sector with the dislocation bunch parallel to the sample surface. Fig. 1.5 demonstrates a set of plane wave X-ray topographs of z-cut of KDP crystal LLNL \#125 with the dislocation bunch parallel to the sample surface in the prism sector a' of crystal (dislocation images are vertical on the topographs). The small rotations in this sample are one order of magnitude bigger than in the previous one.

It is clear from the previous data that the dislocations produce mainly rotation distortions in the KDP and DKDP crystals whereas the differently oriented growth steps build the crystal with slightly different lattice parameters. Therefore the grown crystals have stress condition complicated enough which is a result of dislocation structure specific for each crystal and vicnal hillocks positions on the crystal faces as well as growth parameters.

\section{ROLE OF VICINAL SECTORALITY IN STRIATIONS FORMATION IN KDP AND DKDP CRYSTALS}

Conventional widespread concepts of striations formation are associated with a nonuniform impurity distribution normally to the crystallization front which is caused by fluctuations of growth conditions (supersaturation $\sigma$, growth temperature $T$, etc.) [1]. These 
concepts take into account possible variations in the growth rate of a face as a whole and in the most of cases ignore face morphology and the real structure of the crystal.

The laser-interference methods developed for studying the face morphology of crystals growing from solutions and their growth kinetics [2-5] have been allowed to observe in situ crystal growth via formation of vicinal hillocks on dislocations. As was shown in [6,7], and in the previous reports, the methods of X-ray topography allow to reveal and make clear some mechanisms of inhomogeneity formation in crystals during their growth if one takes into account real growth conditions of crystals.

\section{FORMATION OF STRIATIONS DUE TO ACTIVITY CHANGES OF DISLOCATION SOURCES OF STEPS}

The vicinal hillocks at the points of outcrop of dislocations or dislocation bunches are built by growth steps which have, in the ideal case, the same heights equal to the lattice parameter of the crystal. During the growth process, these steps propagate from the hillock top to the face edge with a velocity

$$
v=\beta_{1} \omega c_{\mathrm{e}}(1-\omega c)^{-1} \sigma \approx \beta_{1} \omega c_{\mathrm{e}}\left(1-\omega c_{\mathrm{e}}\right)^{-1} \sigma \approx \beta_{1} \omega c_{\mathrm{e}} \sigma,
$$

where $\beta_{1}$ is the kinetic coefficient of the step, $\omega=\rho^{-1}$ is the specific volume of the particle in the crystal, and $c_{\mathrm{e}}$ and $c$ are the equilibrium concentration and the concentration during growth in the solution, respectively [1,3]. Neglecting two-dimensional nucleation, one can write the normal growth rate $R$ of the face (along the normal to the singular face orientation) as

$$
R=p v,
$$

where $p$ is the slope of the vicinal surface tilted to the singular face.

If a vicinal hillock is formed by a group of dislocations with the total screw component of their Burgers vectors equal to $\mathrm{mh}$, then, in accordance with [8], the slope of the vicinal hillock is

$$
p=m h /\left(19 \rho_{\mathrm{c}}+2 L\right) \text {. }
$$

Here $2 L$ is the perimeter of the dislocation source of steps, $\rho_{\tilde{n}}=\omega \alpha_{1} / h k T \sigma$ is the critical radius of a two-dimensional nucleus, $\alpha_{1}$ is the specific linear energy of the growth step, $h$ is the step height, $k$ is the Boltzmann constant, and $T$ is the temperature.

\section{DISAPPEARANCE OF OLD AND FORMATION OF NEW VICINAL HILLOCKS}

The distribution of growth steps over the faces of a crystal during growth is not constant. They change not only because of the variations of the external growth conditions but also because of some internal factors. We consider some of them. 
Figure 2.1 shows an $\mathrm{X}$-ray topograph of the $\mathrm{X}$ cut through the center of a KDP crystal grown at the rate $R_{\mathrm{z}} \cong 10 \mathrm{~mm} /$ day along the Z-axis under the conditions such that the anisotropy of the growth rates of the prismatic and bipyramidal faces was especially well pronounced. This was attained by preparing a seed in such a way that its side faces coincided with the natural $\{100\}$ faces. Thus, the crystal regeneration gave almost no rise to formation of dislocations that could be the powerful sources of steps on the prysm faces. The orientation of growth dislocations in these crystals did not coincide with the Z-axis, and therefore they became inactive when the points of dislocation outcrop approached the face edge to a distance close to the critical-nucleus dimension $\rho_{\mathfrak{n}}$ and ceased generating growth steps. Then vicinal hillocks are formed on other dislocations - either already existing or newly formed. The steps generated by new dislocations have new directions of spreading on the face and density in accordance with the dislocation source position and activity. Therefore some stresses between the old and new layers are formed and give rise to striation. The bands on topographs indicated by number 3 seem to be associated with new dislocation bunches in the specimen formed not because of the changes in the growth conditions (both temperature and supersaturation were gradually varied during crystal growth), but because the leading growth centers ceased generating growth steps when they approached the face edges. It scems that other types of striation in this crystal are formed in the same way, but the dislocations associated with their formation are evidently outside the specimen cross section imaged in the Fig. 2.1. The dark or light band contrast depends on the sign of the change in the lattice parameter in the growth bands. The formation of such contrast on two-dimensional boundaries was repeatedly discussed (see, e.g., $[9,6]$ ).

\section{GROWTH BANDS CAUSED BY MACROSTEPS FORMATION}

It was found in [10] that dislocations in the crystals growing from solutions are oriented along directions characterized by the minimum linear energy and do not coincide with the normal to the growing face. This concept was developed in a number of theoretical studies [11, 12] and was confirmed by the experiments on numerous crystals grown from solutions. But in some instances, it was found that growth dislocations can substantially deviate from these directions. On the topograph of the X cut of the KDP crystal (Fig. 2.2 a) almost all the dislocations originated from the regeneration zone near the seed. Most dislocation lines have kinks usually formed at the sites of the dislocation intersection with the growth bands. Similar drastic changes in dislocation orientations on growth bands were also observed in KDP, DKDP, ADP and other crystals in [13, 14]. To analyze the dislocation structure, we chose a rectangular region on the topographs shown in Figs. 2.2 a-d and determined the Burgers vectors and the angles $\beta$ formed by dislocation lines and the [001]-axis for some dislocations indicated in Fig. 2.2. The data obtained are listed in the Table 2. 
In agreement with [10], the orientation of growth dislocations characterized by the vector $l$ corresponds to the direction along which the dislocation has the minimum elastic energy

$$
W=E / \cos \alpha, \quad E=K b^{2} \cdot \ln \left(R / r_{0}\right) / 4 \pi
$$

Here $E$ is the elastic energy per unit length of the straight dislocation, $R$ and $r_{0}$ are the radii of the external and internal cylinders between which the linear dislocation energy is calculated, $b$ is the magnitude of the Burgers vector, $\alpha$ is the angle formed by $l$ and $n$, and $K$ is the energy parameter dependent on $\boldsymbol{l}, \boldsymbol{b}$, and the elastic constants of the crystals.

The directions characterized by the minimum elastic energy in growth sectors of the $\{100\}$ and $\{011\}$ prismatic and dipyramidal faces, respcctively, for most widespread dislocations in KDP crystals characterized by the Burgers vectors $b=[100],[001],[110]$, [011], and 1/2[111] were determined by Fishman [13].

The orientations of all the dislocations observed in regions I and III in Fig. $2.2 \mathrm{~d}$ almost coincide with the calculated orientations (Table 2), but in region II, the orientations of dislocations $1,1 \mathrm{a}, 3$, and $4 \mathrm{a}$ drastically change, so that they nearly coincide with the optimum orientation calculated for the growth sector of the prismatic face. The orientation of dislocation 1a in region IV differs from its orientations in I-III. Lines 5 are the images of dense bunches of dislocations with various Burgers vectors (their contrast remains almost constant under various imaging conditions).

It follows from (4) that the elastic energy per unit length in the growth direction of a dislocation depends on the direction of the Burgers vector $b$ and the surface orientation. Since the Burgers vector of a dislocation does not change its direction during growth, the deviations observed in the experiments can be caused only by the local changes in the orientation of a growing face associated with the existence of vicinal hillocks with stepped slopes on the crystal surface.

The data on the growth kinetics obtained indicate that, at relatively low growth temperatures, these crystals show the propensity to form macrosteps, whereas at $T \approx 50^{\circ} \mathrm{C}$ and higher temperatures, macrosteps behave as groups of elementary steps.

If growth proceeds by the propagation of elementary steps, the orientations of growth dislocations almost coincide with the direction corresponding to the minimum dislocation energy for a singular face. In the case where elementary steps are grouped to form macrosteps or shock waves $[3,15,16]$, the average slope of the surface at the point of the outcrop of dislocation changes, which should result in the corresponding change of the dislocation orientation.

Let us consider that in addition to elementary steps, a growing surface has also relatively large macrosteps, whose front can be represented as a region of the face having an orientation different from that of the remaining part. Then, at the moment of the macrostep passage through the point of the dislocation outcrop on the surface (point 1 in Fig. 2.3), the orientation of this 
dislocation should change in accordance with formula (4). Upon macrostep passage, - the dislocation orientation is restored (point 2 in Fig. 2.3) if a macrostep is followed by elementary steps. This process is accompanied by the formation of two kinks, e.g., such as is shown in Figs. $2.2 \mathrm{~b}$ and $2.2 \mathrm{c}$. So, dislocations can indicate formation of macrosteps on the growing surface of crystal. It is clear from above that macrosteps can be a reason for striations formation: since the surface orientation of the macrostep front, its structure, etc. differ from those in the terraces between steps, the concentration of adsorbed impurities on the macrostep front should also be different. It results in the formation of X-ray topographic contrast at the edges of the region grown during macrostep passage.

A crystal plate cut from the prism sector of DKDP crystal $K$ 4-96 grown with average rate $\sim 7 \mathrm{~mm} /$ day along $\mathrm{z}$-axis is shown in the Fig. 2.4. The plate was cut through the vicinalsector boundary not far from the top of the vicinal hillock marked by black spot in the Fig. 2.4 a. Double crystal topographs Fig. 2.4 b show part of this plate with vicinal-sector boundary at the central region of the images. They show a small difference in the lattice parameters between

the neighboured vicinal sectors $\left(\Delta \mathrm{d} \sim 5 \cdot 10^{-7}\right)$. Additionally, they are rotated at an average angle $1.2 \cdot 10^{-2}$ arc sec. X-ray topographs show striations formed by macrosteps during crystal growth. The variations of the lattice parameters along A-A direction is shown in the Fig. $2.4 \mathrm{c}$. Apparently, a period of oscillations $\sim 100 \mu$ shows an approximate height of macrosteps because it does not correlate neither with temperature oscillations in crystallizer nor crystal reverse rotation period.

\section{GROWTH BANDS FORMED DUE TO MODIFICATION OF VICINAL HILLOCK MORPHOLOGY}

The nonlinear dependences of the tangential velocity $v$ of step propagation and the slopes of vicinal hillocks on supersaturation were first established by Chernov et al. for KDP crystals [5]. Figure 2.5 from Rashkovich [4] shows the slope and the tangential growth rate of steps as functions of supersaturation along two directions on the prismatic face of a KDP crystal characterized by the minimum and maximum tangential growth rates, respectively, curves 1 and 2 in Fig. 2.5. It is clearly seen that with an increase of supersaturation, both slopes, $p_{1}$ and $p_{2}$, and the tangential growth rates, $v_{1}$ and $v_{2}$, drastically change at $\sigma=\sigma_{*}=4.5 \%$. These changes of the vicinal-hillock geometry are explained in [4] by the necessity for steps to "overcome" the blocking effect of impurities on the crystal surface.

Such changes in the morphology of a growing crystal surface result in the formation of striations visible on $\mathrm{X}$-ray topographs of crystals. The projection $\mathrm{X}$-ray topographs of the $\mathrm{Z}$ cut of a KDP crystal LLNL \#174 grown under a varying supersaturation are shown in Figs. $2.6 \mathrm{c}$ and $2.6 \mathrm{~d}$ (the corresponding variations of the supersaturation during growth is shown in Fig. 
$2.6 \mathrm{~b}$ ). One can see the boundary $\mathbf{S A}$ between the adjacent prismatic and dipyramidal growth sectors indicated in the scheme in Fig. $2.6 \mathrm{a}$ and also the tilted sector boundaries SB. At first, the crystal grew rapidly on a point seed $S$ under the supersaturation $\sigma>\sigma_{*}$ (Fig. 2.6 b). Then, with a decrease in the supersaturation, the growth rate also decreased. Upon the attainment of a certain supersaturation $\sigma_{*}$, the morphology of vicinal hillocks on the topograph changed, which resulted in the appearance of the first growth band. Upon certain time during which a crystal layer corresponding to growth under supersaturation $\sigma<\sigma_{*}$ was formed, the growth temperature was decreased at a higher rate. This increased the supersaturation again, and at $\sigma=$ $\sigma_{*}$, the second band was formed with the corresponding restoration of the vicinal hillock morphology on the prismatic faces. This experiment allowed us to estimate $\sigma_{*}$ value for this crystal as $3.0-3.5 \%$. The $\mathrm{X}$-ray topographic contrast shows that lattice parameters in the band corresponding to the slow growth rate is slightly different compared to the areas of crystal grown at higher growth rates. Unfortunately, the accuracy of the growth rate and supersaturation measurements during the bulk growth are not enough to find out the exact reason of the striations which are seen in the layer of the slow growth. They can be connected with variations of temperature (and supersaturation) which are typically higher in absolute value at fast growth. However, it is clear from the topographs Fig. $2.6 \mathrm{c}$,d that the striations are much more pronounced in the area grown at $\sigma<\sigma_{*}$ as compared with rapidly grown area.

\section{CONCLUSION}

The plane wave X-ray topography method of quantitative evaluation of crystal homogeneity has been developed. Its efficiency is demonstrated above on rapidly grown KDP and DKDP crystals. The method can be useful for studying the effect of various growth parameters on the crystal quality and for studying of mechanisms of some defects formation.

It was shown by $\mathrm{x}$-ray topography methods that the lattice parameters of a crystal growing due to step propagation along the vicinal surface are different on different vicinal faces of the same hillocks and are dependent on the growth-step orientation. This kind of inhomogeneity was named "vicinal sectorality" just as sectoral structure of crystals formed by growth of whole faces. The nonuniform stoichiometric composition or incorporation of impurities into various vicinal sectors on the crystal faces results in different average values of the crystal lattice parameters, which can be revealed and measured by X-ray topography.

It was found in the crystals KDP and DKDP that the dislocations produce mainly rotation distortions whereas the differently oriented growth steps build the crystal with different lattice parameters. Therefore each grown crystal is in a stress condition complicated enough 
which is a result of dislocation structure and vicnal sectors distribution in crystals as well as growth parameters.

Formation of various inhomogeneities in crystals can be caused not only by the variations of the external growth conditions, but also by the action of some "internal" factors, and, first of all, by the variations in the dislocation structure of the crystal. The main mechanisms of striations formation are related with redistribution of growth steps on the crystal surface, because steps with different orientations capture impurities quite differently. This results in the variation of the lattice parameter. As far as no way to eliminate dislocatons from the crystal as well vicinal hillocks formed by them and related vicinal sectorality, the described kinds of inhomogeneity has to be found in all crystals growing by layer mechanism.

\section{REFERENCES}

1. Chernov, A.A. in "Modern Crystallography", Berlin: Springer, 1984, vol. 3.

2. Chernov, A.A., Rashkovich, L.N., and Mkrtchan, A.A., Solution Growth Kinetics and Mechanism: Prismatic Face of ADP, “J. Cryst. Growth”, 1986, vol. 74, no. 2, pp.101-112.

3. Chernov, A.A., Rashkovich, L.N., Smolsky, I.L., Kuznetsov, Yu.G., Mkrtchan, A.A., and Malkin, A.J., Processes of crystal growth from aqueous solutions (KDP group). In: "Growth of Crystals":, Givargizov, E.I., Ed., New York: Consultants Bureau, 1988, vol. 15 , p. 43.

4. Rashkovich, L.N., KDP-Family Single Crystals, Bristol: Adam Hilger, 1991.

5. Chernov, A.A., Rashkovich, L.N., and Mkrtchan, A.A., Optical -Interference nvestigation of Surface Processes of Growth of KDP, DKDP, and ADP Crystals, Soviet Physics "Crystallography", 1987, vol. 32, no. 3, pp.432-442.

6. Smolsky, I.L., Chernov, A.A., Kuznetsov, Yu.G., Parvov, V.F., and Rozhanskii, V.N., Vicinal Sectoriality and Its Relation to Growth Kinetics of ADP Crystals, Sov. Physics “Doklady", 1984, vol. 29, no. 9, pp.703-705.

7. Smolsky, I.L., Chernov, A.A., Kuznetsov, Yu.G., Parvov, V.F., and Rozhanskii, V.N., Vicinal Sectoriality in the Growth Sectors of the (101) Faces of ADP Crystals, Sov. Physics "Crystallography”, 1985, vol. 30, no. 5, pp. 563-566.

8. Burton, W.K., Cabrera, N., and Frank, F.C., The Growth of Crystals and the Equilibrium Structure of Their Surfaces, "Philos. Trans. Roy. Soc. London A,“ 1951, 243, p. 299.

9. Fishman, Yu.M. and Lutsau, V.G., X-ray Dynamical Diffraction Contrast Due to Inhomogeneous Impurity Distribution, "Phys. Status Solidi”, 1970, vol. 3, no. 2, pp. 829-837.

10. Klapper, H., Fishman, Yu.M., and Lutsau, V.G., Elastic Energy and Line Directions of Grown-in Dislocations in KDP Crystals, "Phys. Status Solidi (A), 
1974, vol. 21, no. 1, pp. 115-129.

11. Indenbom, V.L., Alshits, V.I., and Chernov, V.M., "Defects in Crystals and Their Computer Simulation", Leningrad: Nauka, 1980, p. 23.

12. Chernov, A.A. and Dimitrov, V.S., Interaction between dislocations and cellular front of crystallization: (0001) $\mathrm{SiO}_{2}$ face, "J. Cryst. Growth", 1989, vol. 96, p. 304-315.

13. Fishman, Yu.M., X-Ray topographic study of the dislocations produced in $\mathrm{KH}_{2} \mathrm{PO}_{4}$ crystals by growth from solution, Sov. Physics "Crystallography", 1972, vol. 17, p. 607-619.

14. "Characterization of Crystal Growth Defects by X-ray Methods," Tanner, B.K. and Bowen, D.K., Eds., New York: Plenum, 1980.

15. Chernov, A.A., Kuznetsov, Yu.G., Smolsky, I.L., and Rozhanskii, V.N., Hydrodinamic effects in growth of ADP crystals from aqueous solutions in the kinetics regime, Sov. Physics "Crystallography", 1986, vol. 31, No 6, p. 705-709.

16. Chernov, A.A., How does the flow within the boundary layer influence morphological stability of a vicinal face?, “J. Cryst. Growth", 1992, vol. 118, p. 333-347. 


\section{FIGURE CAPTIONS}

Fig. 1.1. Plane wave double crystal X-ray topographs of the central part of Z-cut of crystal LLNL \#125. Analysis of distribution of distortions between the crystal sectors. Reflection geometry, $\mathrm{Cu} \mathrm{K} \alpha_{1}$ irradiation, reflection $\mathrm{g}$ - [008]. (a), (b) are the experimental topographs. (c) is a calculated distribution of the lattice parameter changes; (d) is a calculated distribution of small rotations of crystal lattice. The dipyramidal growth sectors have more light contrast than prismatic ones.

Fig. 1.2. Plane wave double crystal X-ray topographs of the part of X-cut of crystal LLNL \#133. Reflection geometry, $\mathrm{Cu} K \alpha_{1}$ irradiation, reflection $\mathrm{g}$ - [400]. (a), (b) are the experimental topographs; (c) is a calculated distribution of the lattice parameter changes; (d) is a calculated distribution of small rotations of crystal lattice. The boundary between areas 1 and 2 is a sectoral boundary; boundaries between areas 2,3 and 4 are intervicinal boundaries.

Fig. 1.3. Plane wave double crystal X-ray topographs of the central part of (101)-cut of crystal

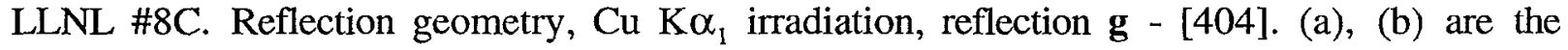
expcrimental topographs. (c) is a calculated distribution of the lattice parameter changes; (d) is a calculated distribution of small rotations of crystal lattice. An intervicinal boundary is seen as a vertical line at the central part of the topographs. Zig-zag lines are steps on the surface formed during preparation of the sample.

Fig. 1.4. Plane wave double crystal X-ray topographs of Y-cut of DKDP crystal K7-97. Deuteration level of crystal $\mathrm{D}=96.7 \%$. Reflection geometry, $\mathrm{Cu} \mathrm{K} \alpha_{1}$ irradiation, reflection $\mathbf{g}=$ [400]. Diffraction vector $\mathbf{g}$ isnormal to the crystal surface. Z-axis is horisontal here. (a), (b) are the experimental topographs. (c) is a calculated distribution of the lattice parameter changes; (d) is a calculated distribution of small rotations of crystal lattice. Black horisontal lines are microcracks formed in the process of the sample preparation.They give an evidence of high level of inhomogeneity of crystal on the whole.

Fig. 1.5. Plane wave double crystal X-ray topographs of the central part of Z-cut of crystal LLNL \#125. Analysis of effect of dislocations on the distortions in crystal plate. Reflection geometry, $\mathrm{Cu} \mathrm{K} \alpha_{1}$ irradiation, reflection $\mathrm{g}$ - [008]. (a), (b) are the experimental topographs. (c) is a calculated distribution of the lattice parameter changes; (d) is a calculated distribution of small rotations of crystal lattice. 
Fig. 2.1. Projection X-ray topograph of the $\mathrm{X}$ cut of a KDP crystal. Mo-K $\alpha_{1}$ radiation, reflection vector $\mathrm{g}$-[020]. (1) seed, (2) sectorial boundaries between the prismatic and bipyramidal faces, (3) striation due to a lower activity of the leading growth hillocks at the face edge and the formation of new dislocation sources of steps.

Fig. 2.2. (a) Projection X-ray topograph of a part of the central crossection of a KDP crystal (X cut), $\mathbf{g}-[020]$. (b), (c) Topographs of a region in rectangular marked on (a). (b): g-[020]; (c): g-[022]. (d) Schematic arrangement of dislocations in a rectangle. Numbers 1-4 indicate dislocations vith different Burgers vectors.

Fig. 2.3. A model of the dislocation orientations changes in the process of macrostep formation.

Fig. 2.4. Striations formation in the prism sector of DKDP crystal (growth rate $R \sim 7 \mathrm{~mm} /$ day along z-axis). a) A diagram of a specimen position with respect to the crystal. A black spot indicates the outcrop point of dislocation bunch. b) Plane wave double crystal topographs of the patr of specimen containing the vicinal-sectoral boundary $(1,2)$ and syntetic images of distribution of the lattice parameter changes (3) and small rotations along the sample surface (4). c) The changes of the lattice parameter a along A-A direction.

Fig. 2.5. The slopes $p_{1}$ and $p_{2}$ and the tangential velocities $v_{1}$ and $v_{2}$ of growth step ropagation along two mutually perpendicular directions of the prismatic face of a KDP crystal as functions of supersaturation; $\gamma$ is the angle formed by the [100] direction and $v_{\max }$. (Data of L.N.Rashkovich [4]).

Fig. 2.6. Formation of growth bands in the sectors of the prismatic face due to changes in the surface morphology at a supersaturation of $\sigma=\sigma_{*}$. (a) Scheme illustrating the orientation of the specimen with respect to the crystal and the sectoral boundaries in it; (b) the graphical representation of the changes in supersaturation during crystal growth, (c, d) projection X-ray topographs of the $\mathbf{Z}$ cut; $\mathbf{S}$ is the seed and $\mathbf{S A}$ and $\mathbf{S B}$ are the sectoral boundaries. 
Table 1. The changes of lattice parameter $a$ and misorientations of dipiramidal vicinal sectors in of the sample \# 133.

\begin{tabular}{|c|c|c|c|}
\hline $\begin{array}{c}\text { Number } \\
\text { of area }\end{array}$ & $\begin{array}{c}\text { Mean } \\
\text { value of } \\
\text { the lattice } \\
\text { changes } \\
\Delta a\end{array}$ & \multicolumn{2}{|c|}{$\begin{array}{c}\text { Mean value of the } \\
\text { small rotations } \omega_{y x} .\end{array}$} \\
\hline & $10^{-7} \mathrm{~A}$ & $\begin{array}{c}\mid 0^{-2} \text { arc } \\
\text { sec }\end{array}$ & $10^{-7}$ \\
\hline 1 & 2.4 & 6.6 & 3.3 \\
\hline 2 & 0.2 & 4.4 & 2.2 \\
\hline 3 & 3.9 & 0.3 & 0.2 \\
\hline 4 & -2.1 & -0.3 & -0.2 \\
\hline
\end{tabular}


Table 2. Angles $\beta$ formed by the dislocation line and the [001] axis for dislocations with various Burgers vectors $\boldsymbol{b}$ observed and calculated in [10] for KDP crystals

\begin{tabular}{|l|r|c|c|c|c|c|l|}
\hline \multicolumn{1}{|c|}{$\begin{array}{c}\text { No } \\
\text { (Fig.3) }\end{array}$} & \multicolumn{4}{c|}{$\begin{array}{c}\text { (Fig.1d) } \\
\text { Crystal region }\end{array}$} & \multicolumn{2}{c|}{$\begin{array}{c}\beta \\
\text { calculated in } \\
{[10]}\end{array}$} & $\begin{array}{c}\text { Burgers vector } \\
\text { b } \\
\text { orientation }\end{array}$ \\
\hline & I & II & III & IV & $(011)$ & $(010)$ & \\
\hline $\mathbf{1}$ & 78 & 86 & 78 & & 78 & 90 & {$[010]$} \\
\hline $\mathbf{1 a}$ & 78 & 86 & 78 & 50 & & & \\
\hline $\mathbf{2}$ & 15 & 4 & 15 & & 16.5 & 90 & {$[001]$} \\
\hline $\mathbf{3}$ & 40 & 90 & 40 & & 50 & 90 & {$[110]$} \\
\hline $\mathbf{4}$ & 29 & 6 & 29 & & & & \\
\hline
\end{tabular}




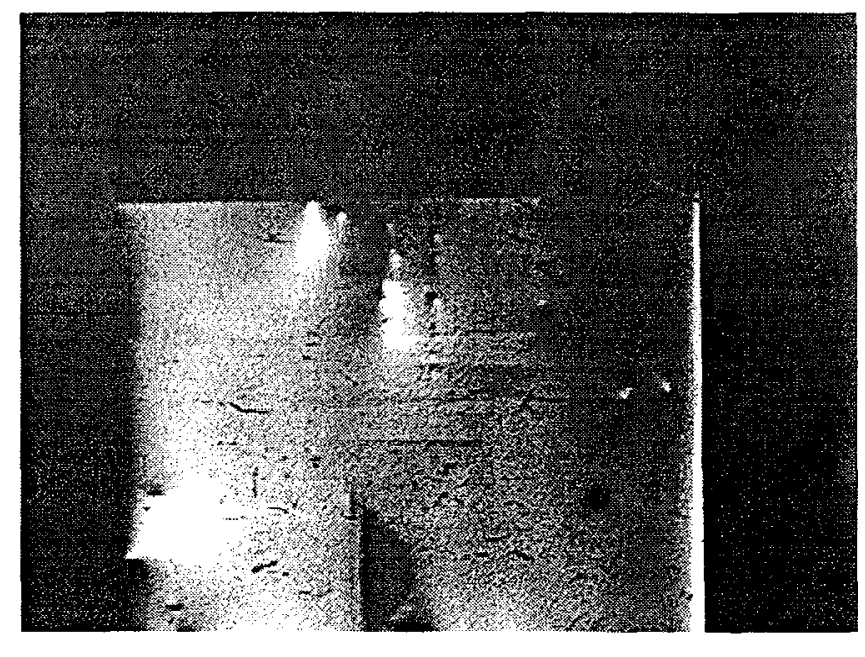

a) Topograph at azimuth angle $\alpha=0$

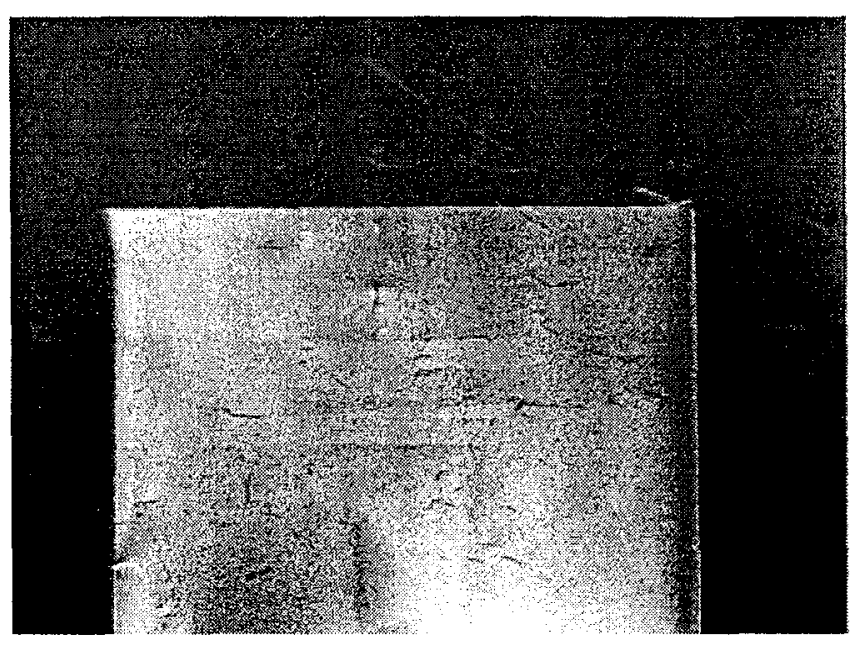

c) Changes of the lattice parameter $\Delta a$

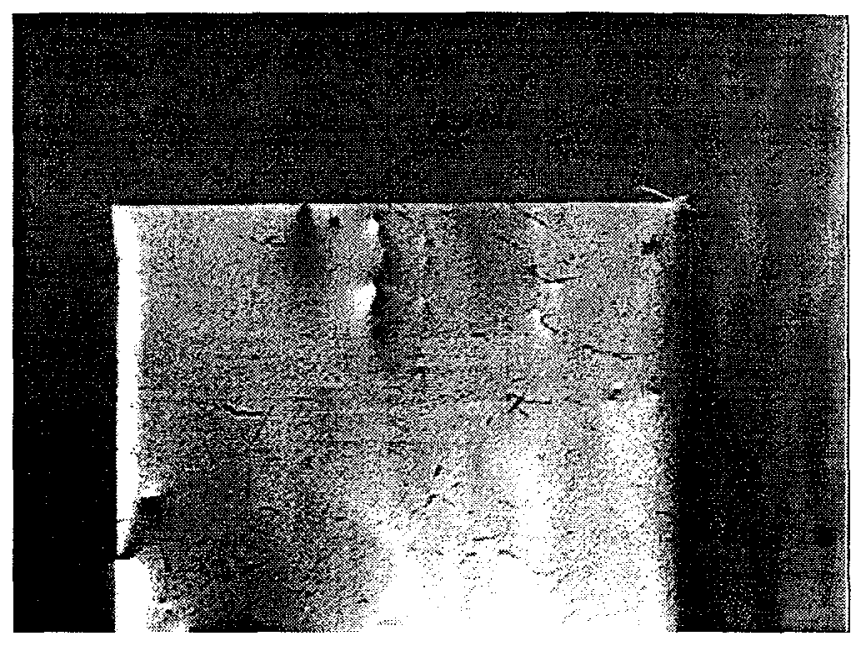

b) Topograph at azimuth angle $\alpha=180$

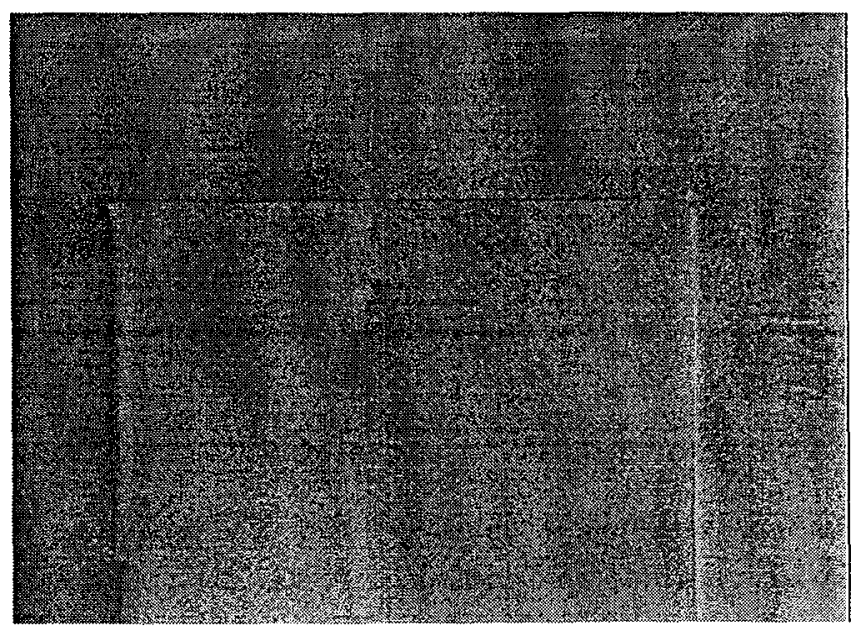

d) Small rotations $w_{y x}$

H125, Z-cut

$\Delta \mathrm{c}=7 \cdot 10^{-6} \AA$

Fin 1.1 


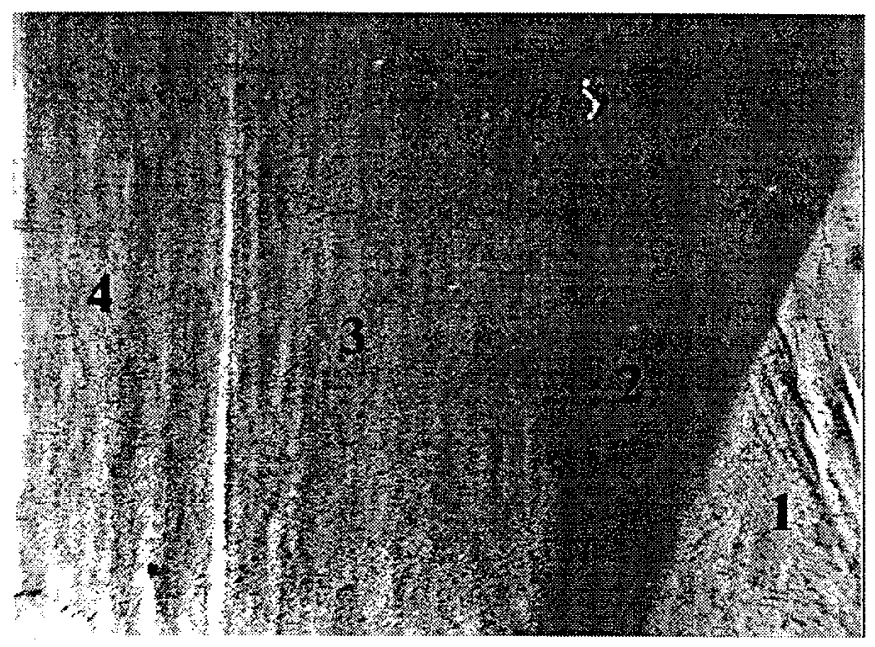

a) Topograph at azimuth angle $\alpha=0$

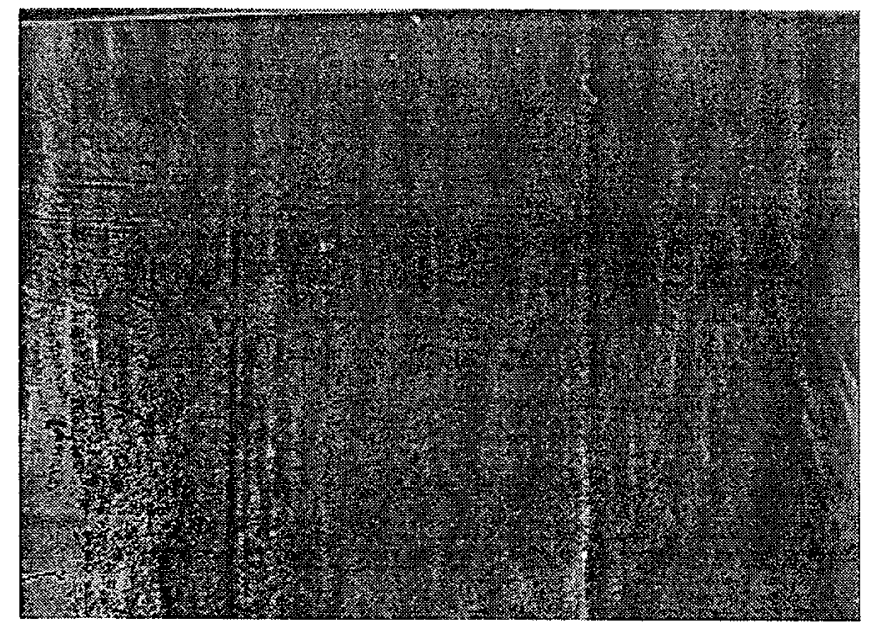

c) Changes of the lattice parameter $\Delta a$

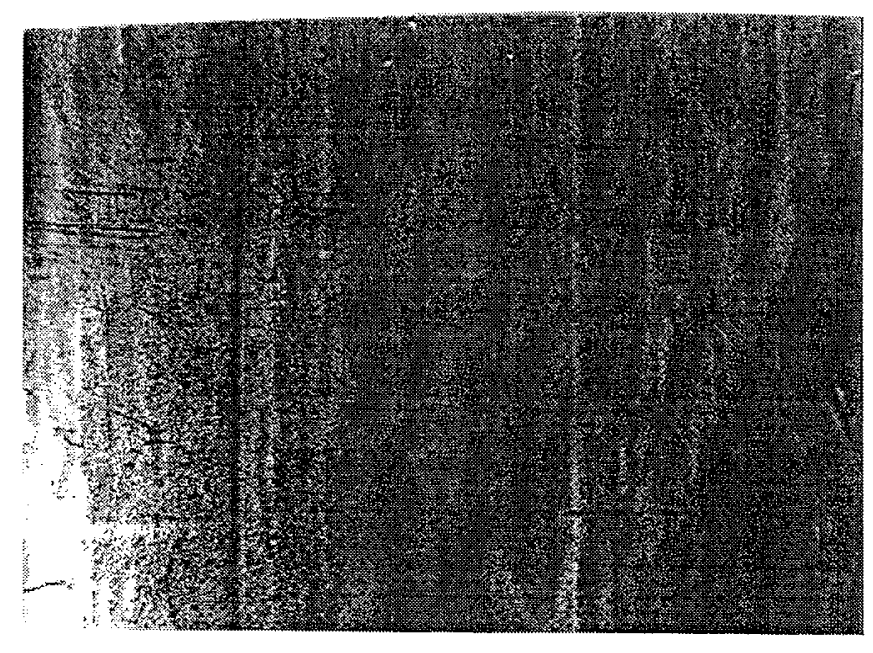

b) Topograph at azimuth angle $\alpha=180$

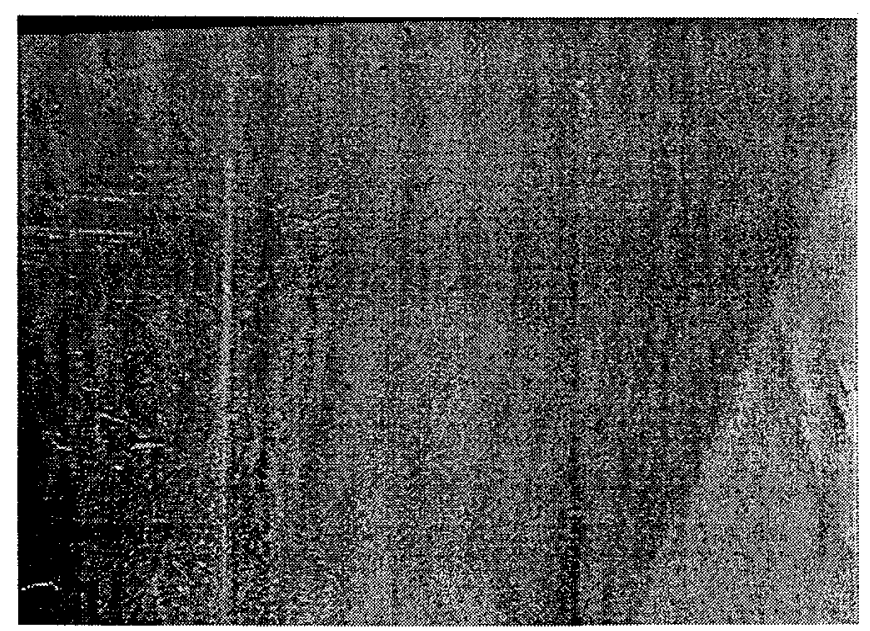

d) Small rotations $w_{y x}$

\#133, X-cut 


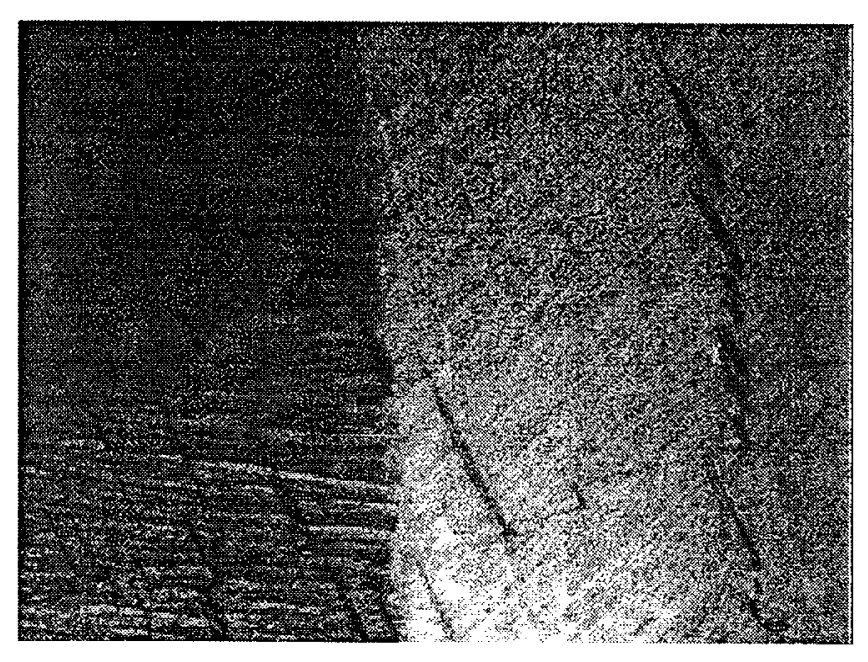

a) Topograph at azimuth angle $\alpha=0$

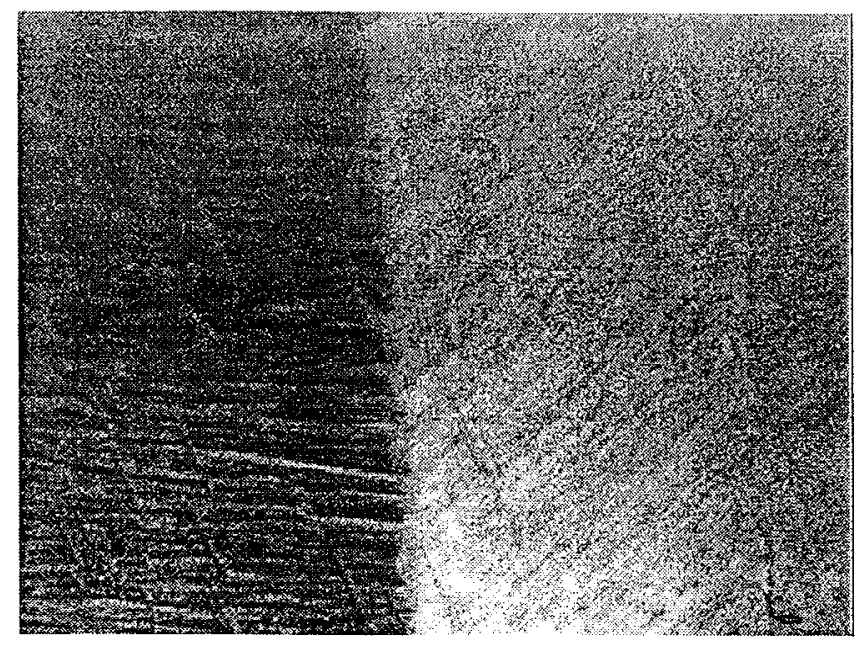

c) Changes of the lattice parameter $\Delta a$

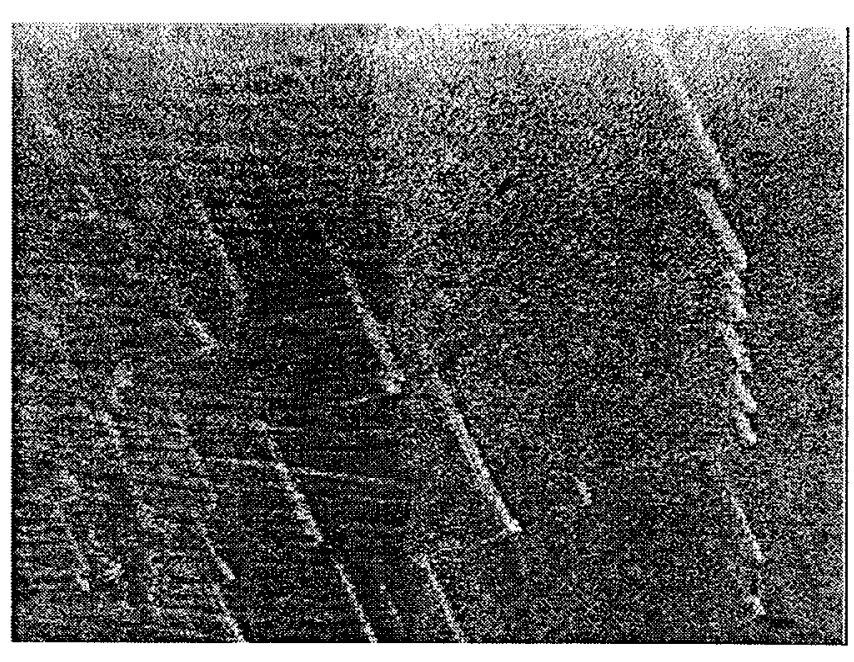

b) Topograph at azimuth angle $\alpha=180$

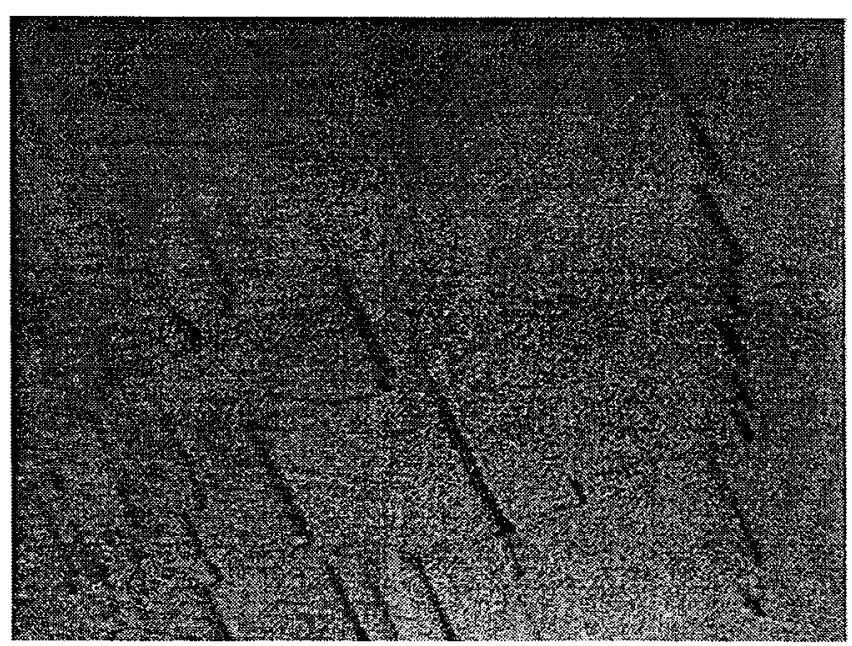

d) Small rotations $w_{y x}$

\# 8c, (101)-cut

$\Delta \mathrm{a}=3.1 \cdot 10^{-5} \AA$ 


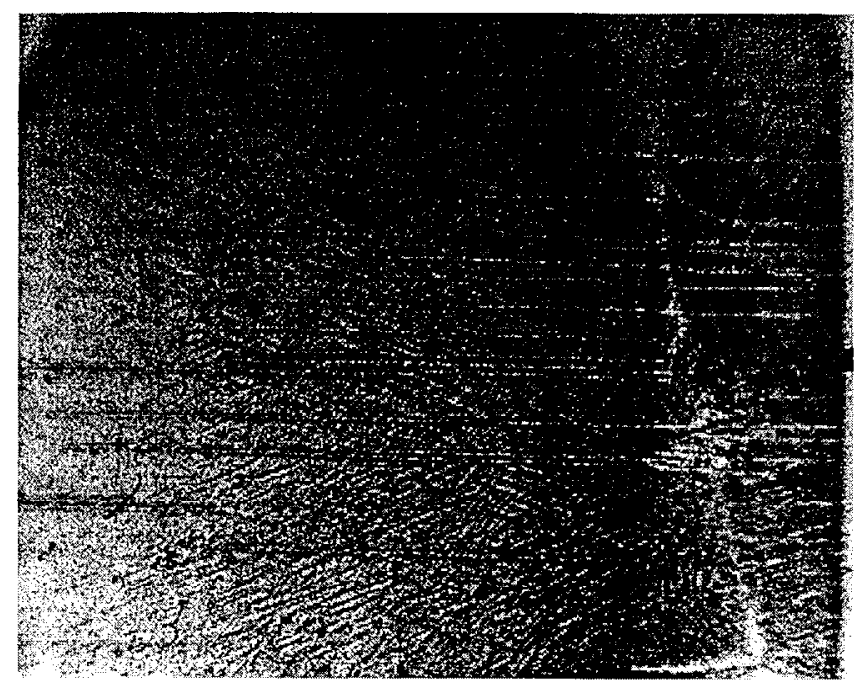

a) Topograph at azimuth angle $\alpha=0$

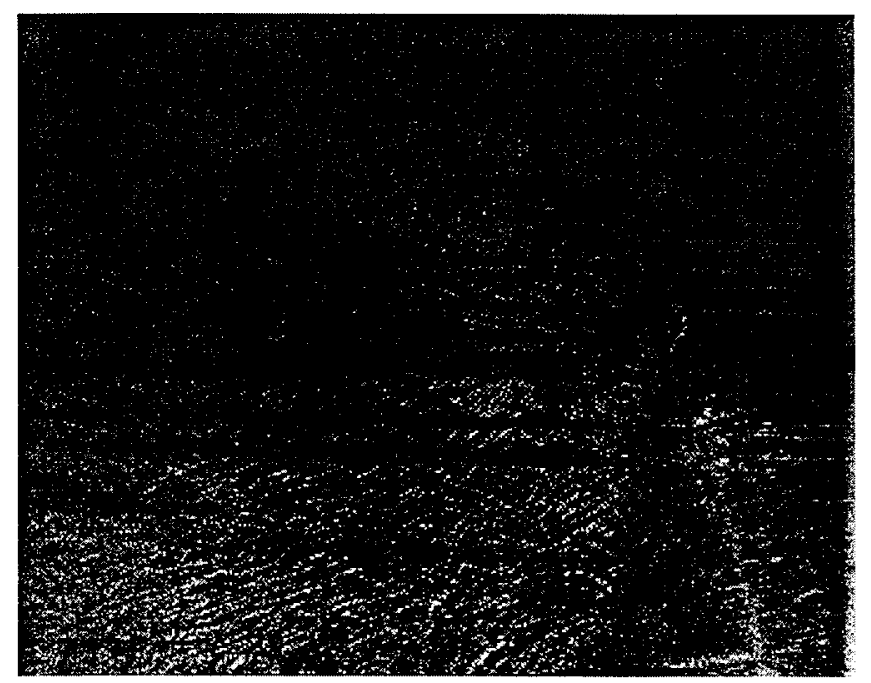

c) Changes of the lattice parameter $\Delta a$

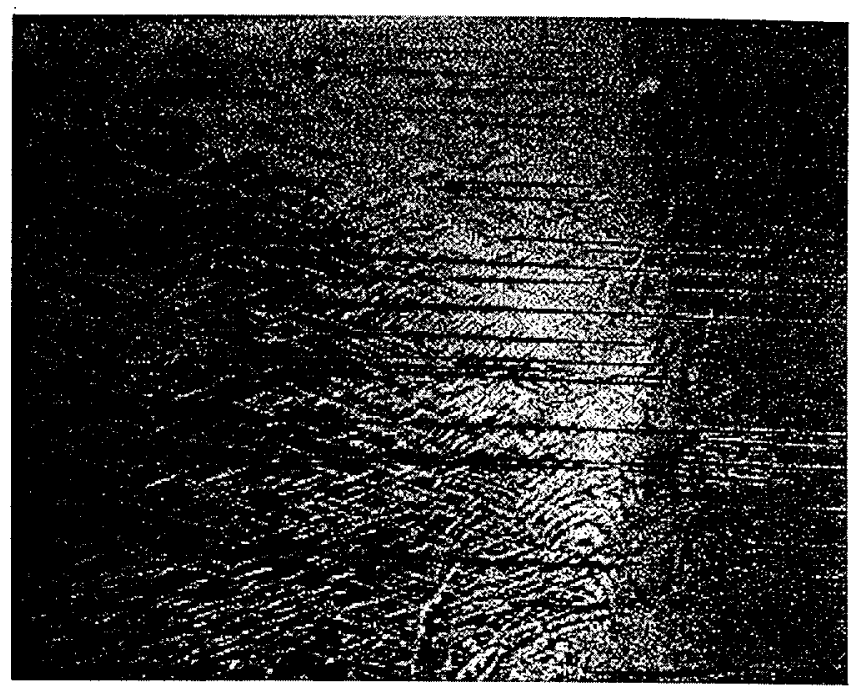

b) Topograph at azimuth angle $\alpha=180$

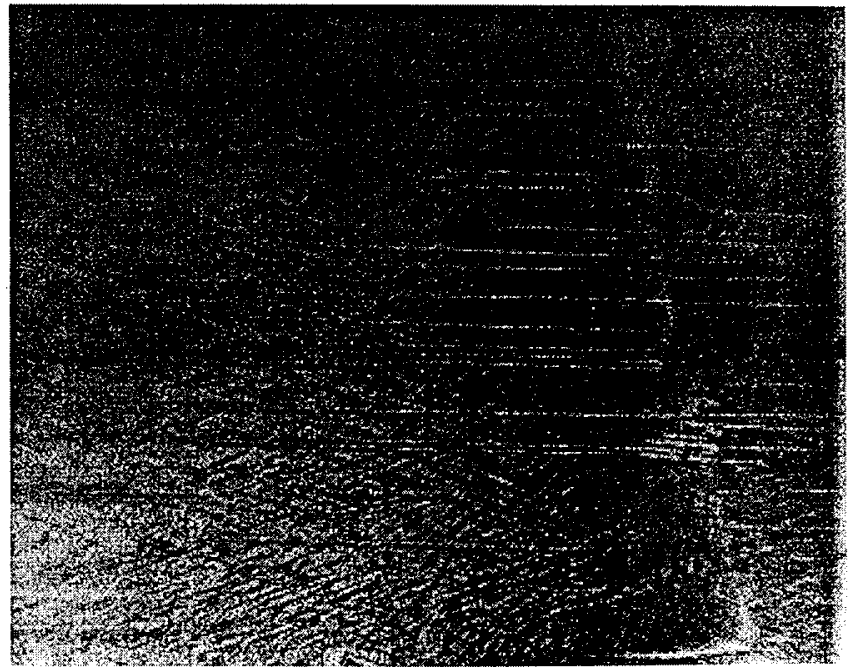

d Small rotations $w_{y x}$

\author{
DKDP, Y-cut \\ $\Delta \mathbf{a}=1.8 \cdot 10^{-7} \AA$ \\ $\Delta \mathrm{w}=1.1 \cdot 10^{-2} \operatorname{arcsec}$
}

Fin 11 , 


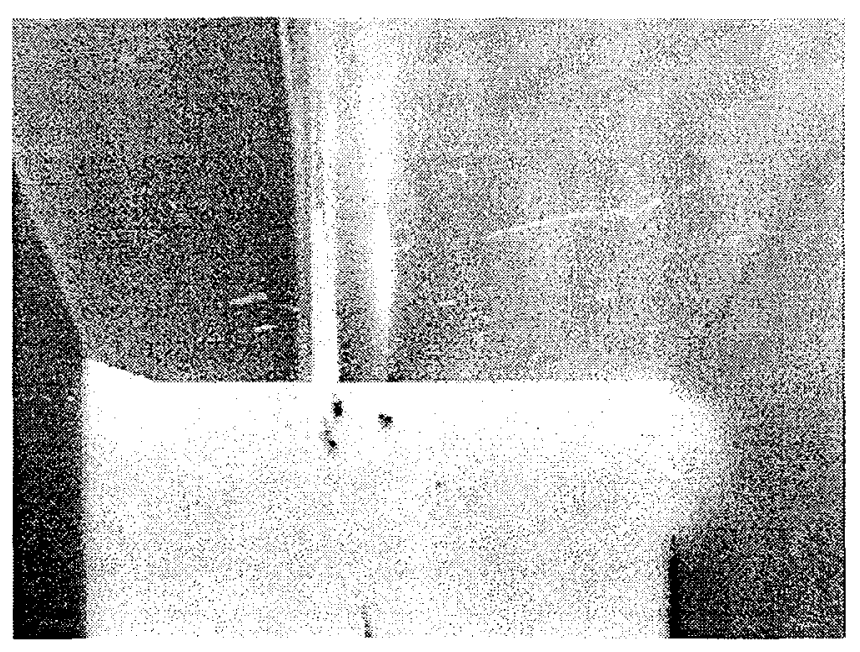

a) Topograph at azimuth angle $\alpha=0$

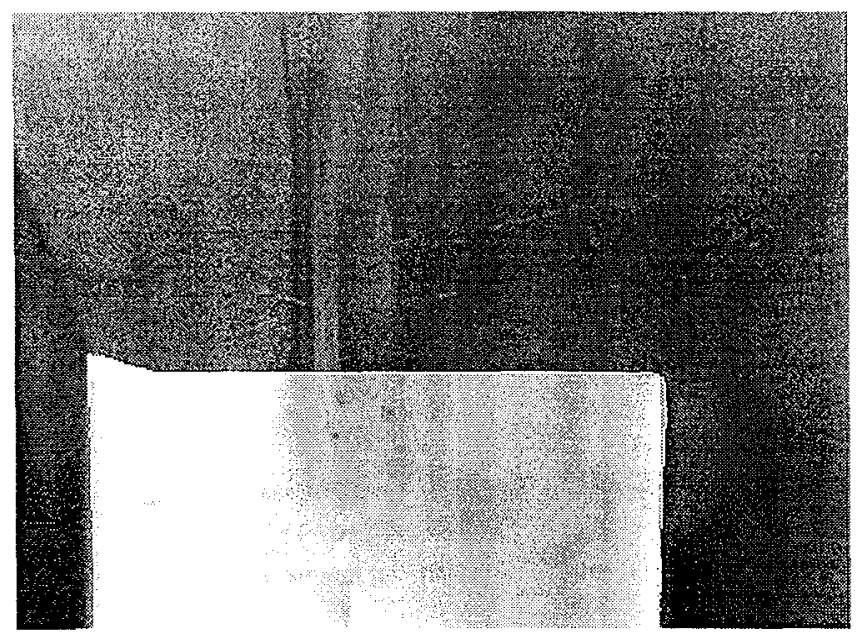

c) Changes of the lattice parameter $\Delta a$

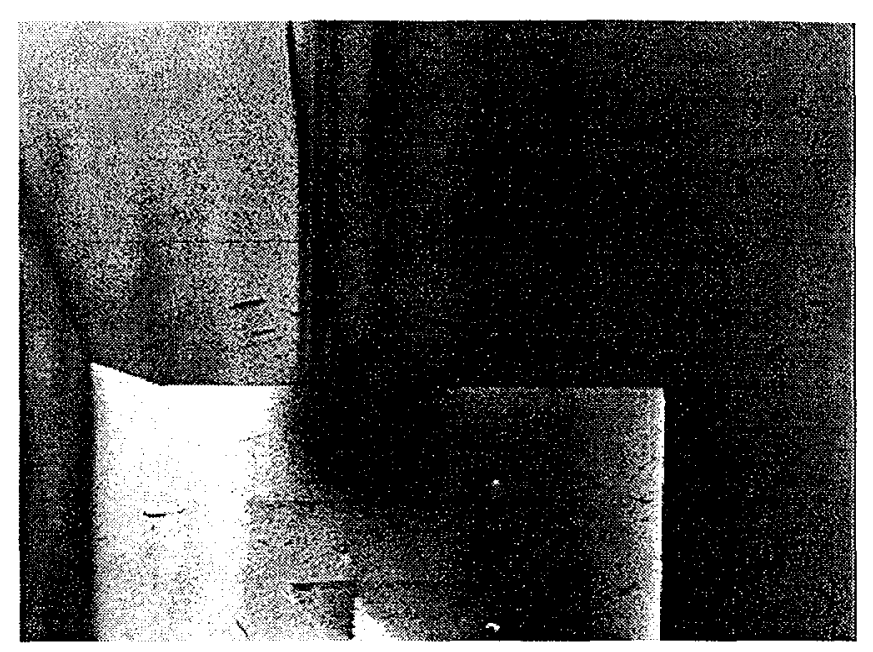

b) Topograph at azimuth angle $\alpha=180$

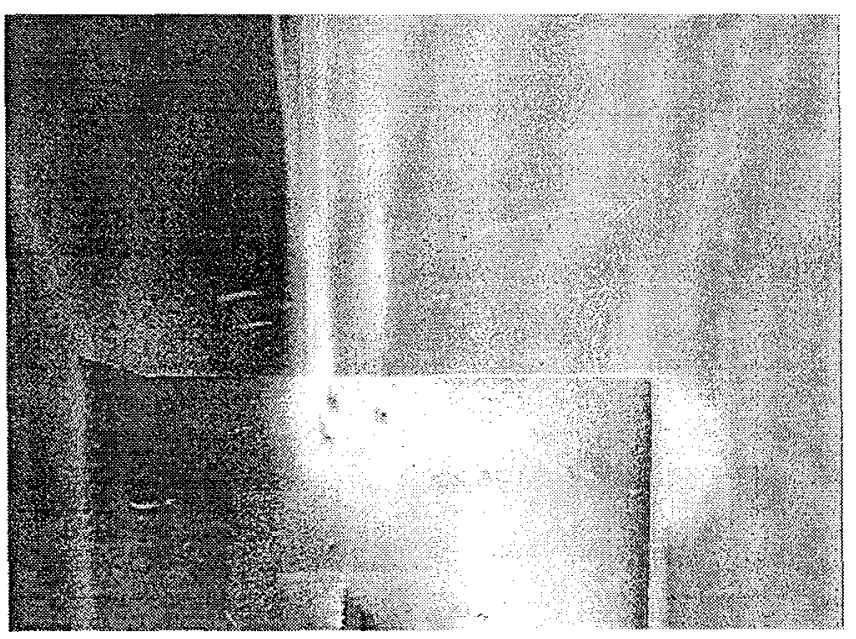

d) Small rotations $\mathrm{w}_{\mathrm{yx}}$

\#125, Z-cut

$$
\begin{aligned}
& \Delta c=1.7 \cdot 10^{-6} \AA \\
& \Delta w=0.3 \operatorname{arcsec}
\end{aligned}
$$




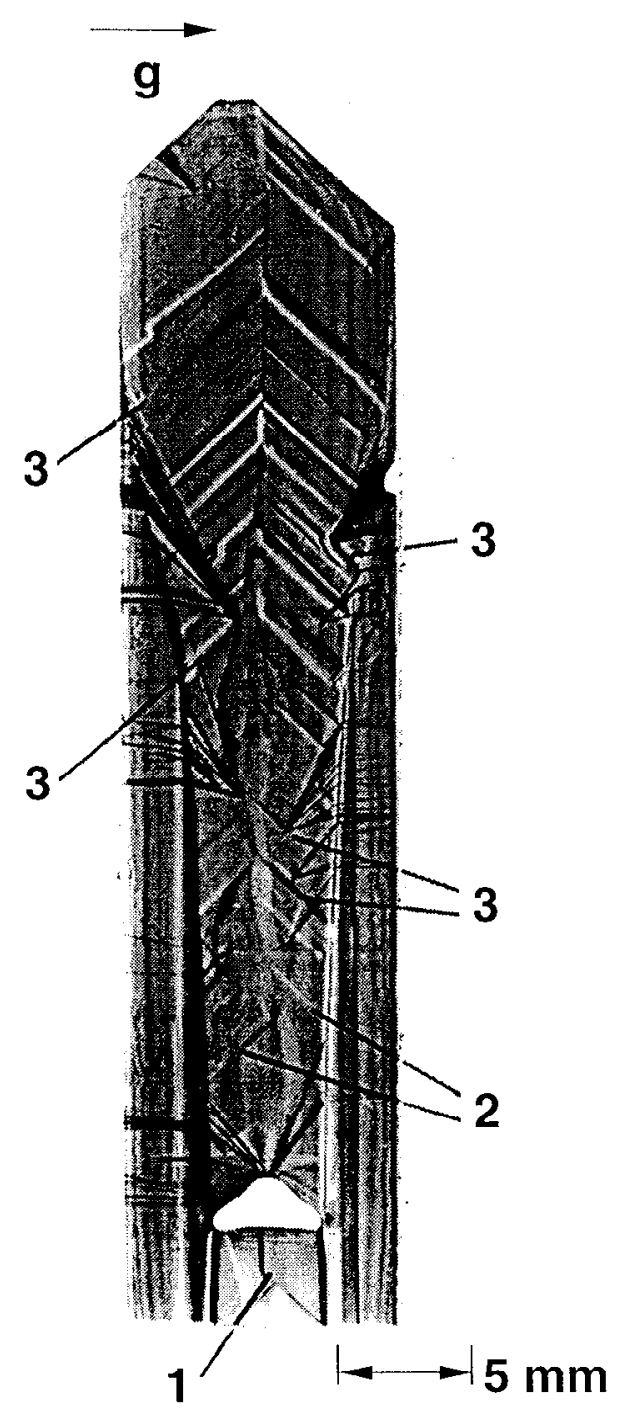

Fig. 2.1 

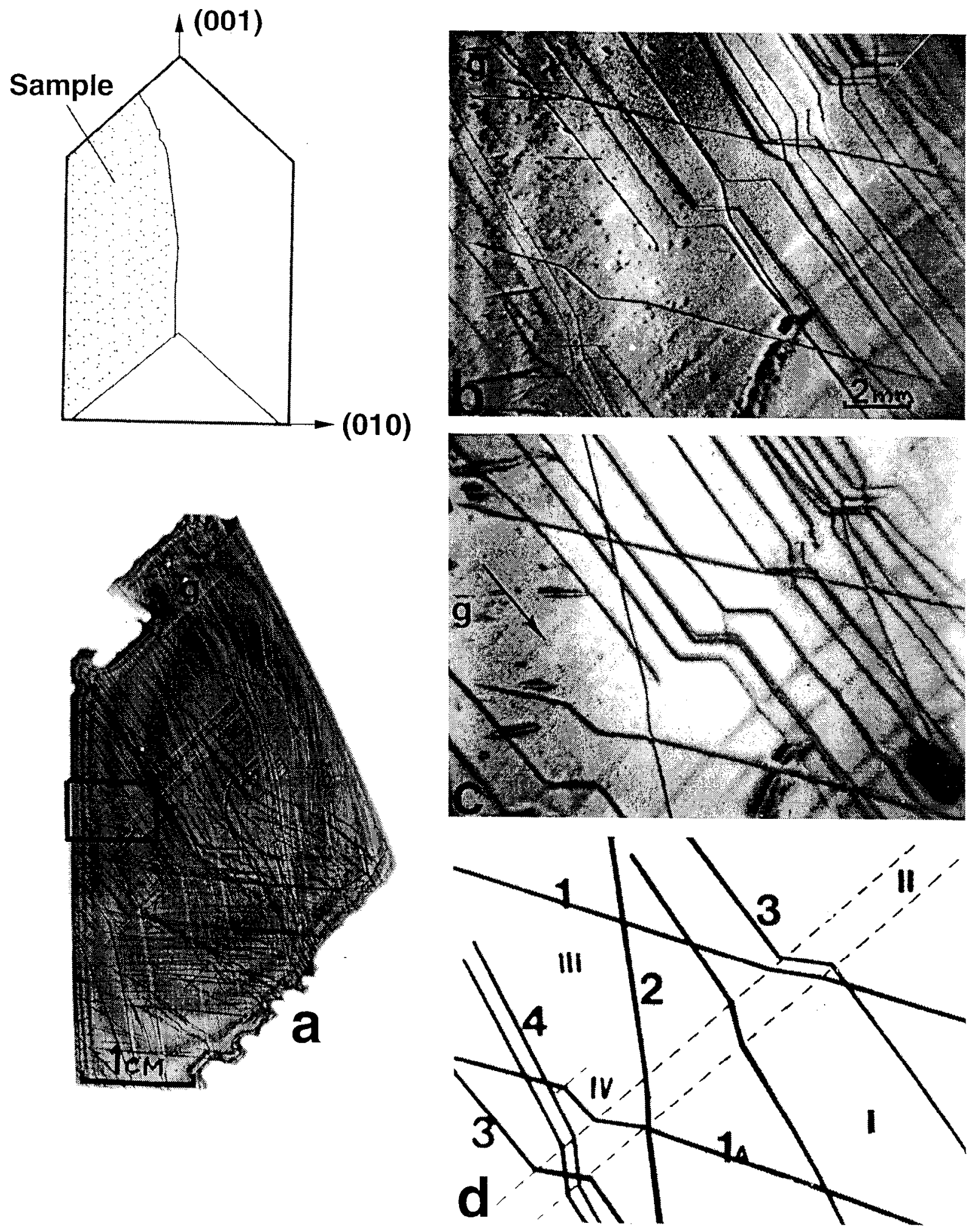


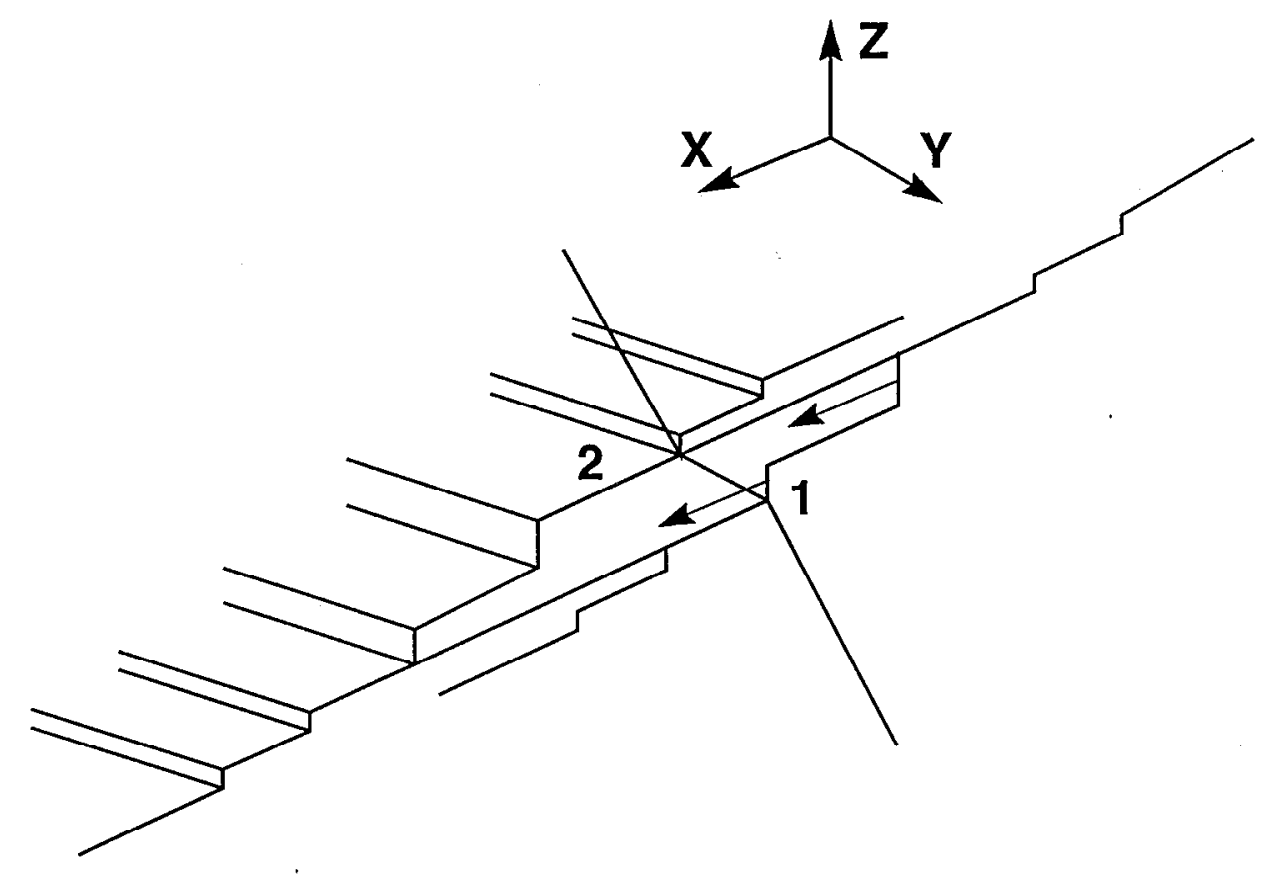

Fic, 23 


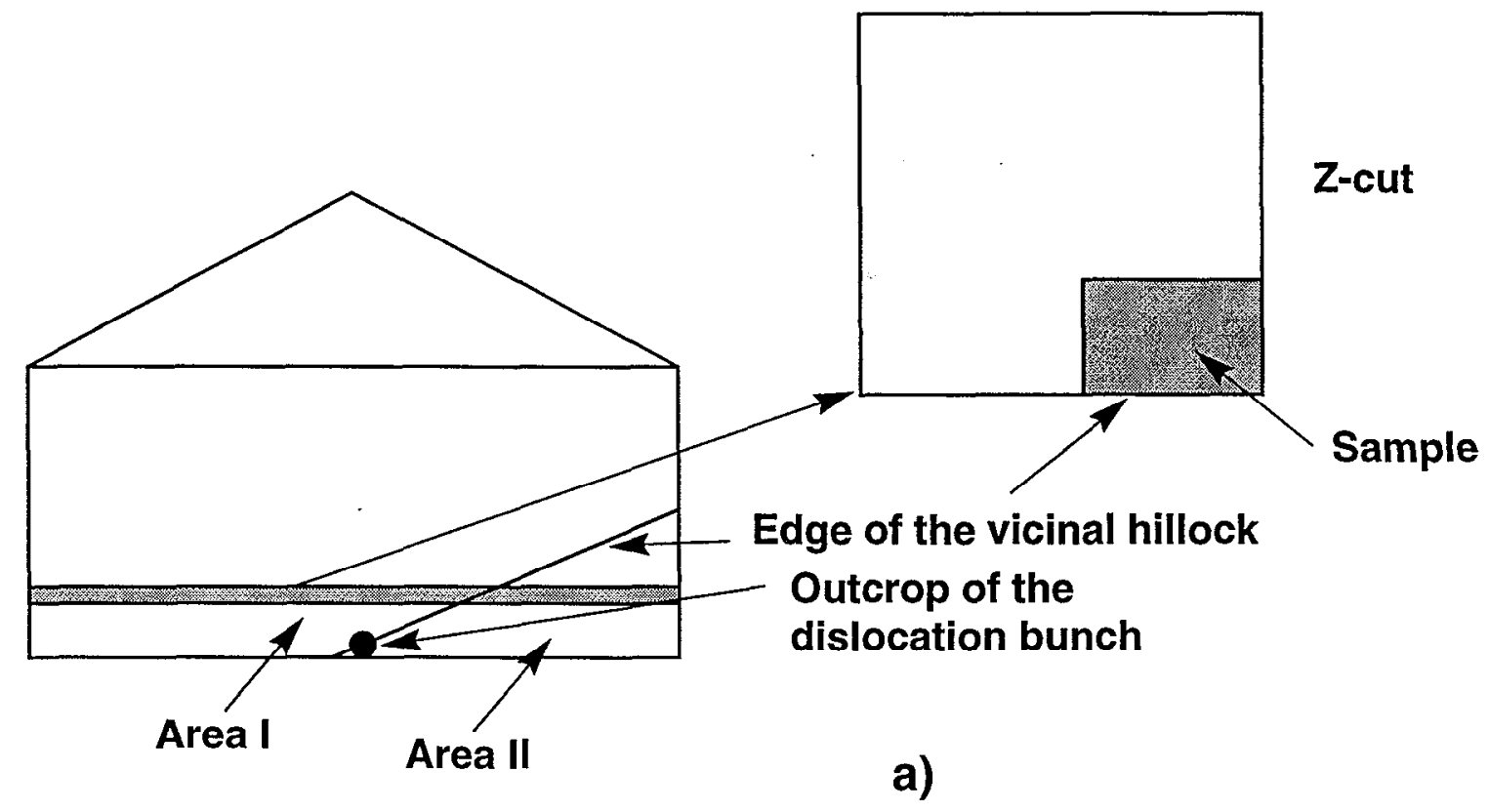

Fia. 2 , $a$ 


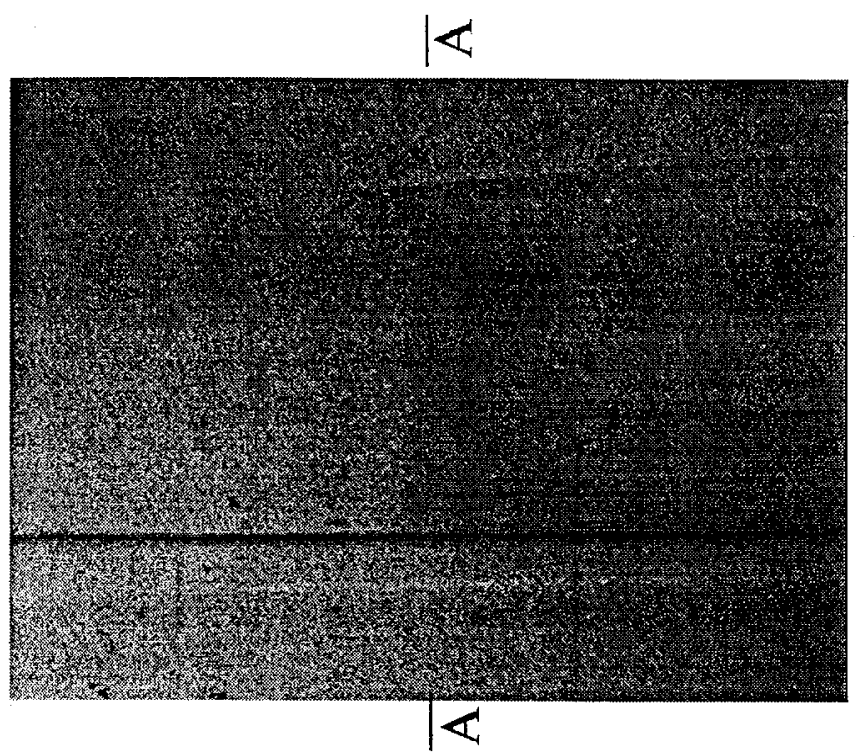

1) Topograph at azimuth angle $\alpha=0$

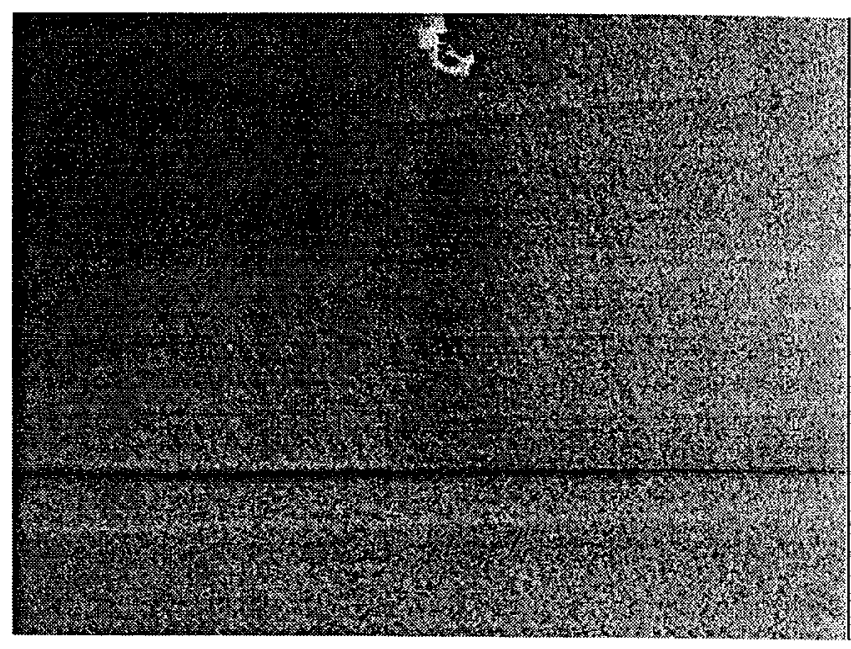

2) Topograph at azimuth angle $\alpha=180$

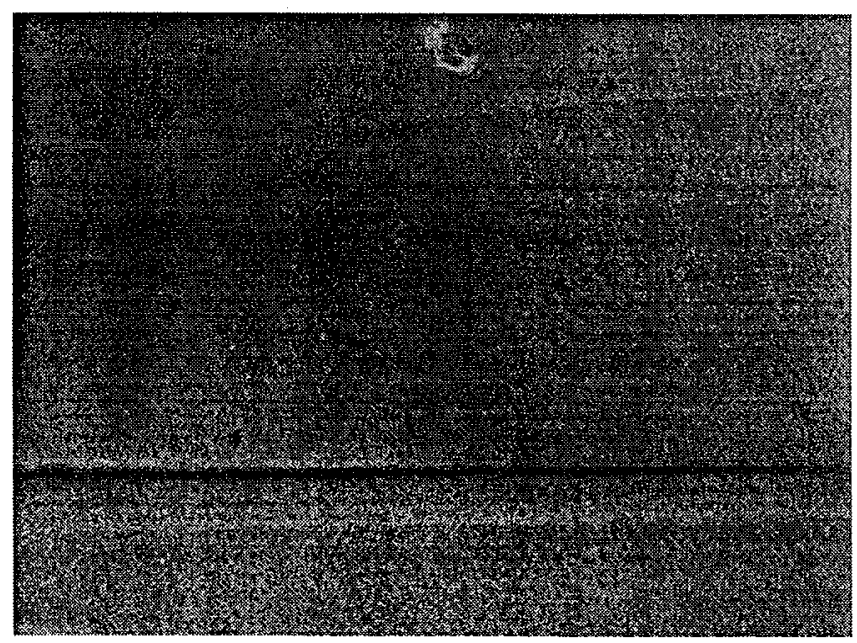

3) Changes of the lattice parameter $\Delta a$

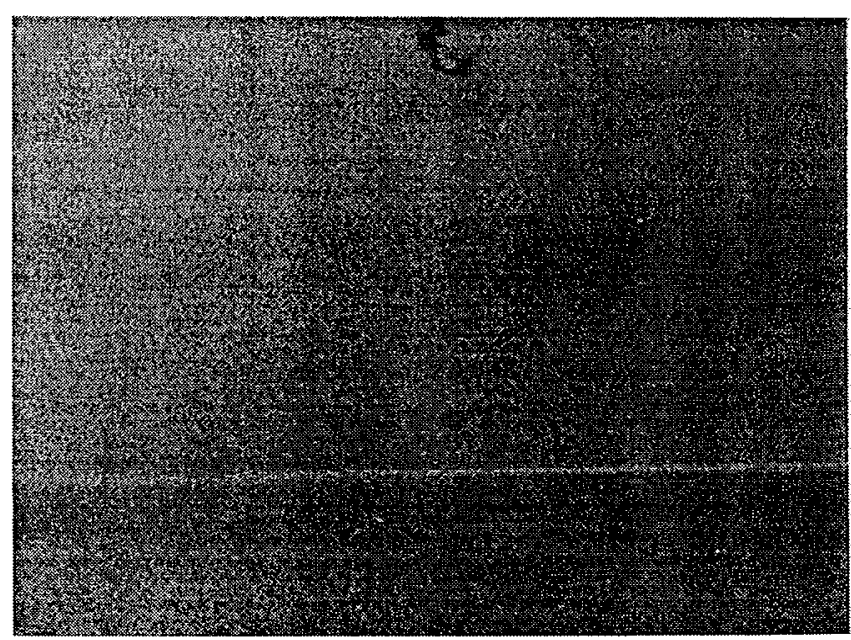

4) Small rotations $w_{y x}$

$$
\begin{gathered}
D K D P, \quad Z-c u t \\
\Delta \mathrm{c}=5 \cdot 10^{-7} \AA \\
\Delta \mathrm{w}=1.2 \cdot 10^{-2} \text { arc sec }
\end{gathered}
$$




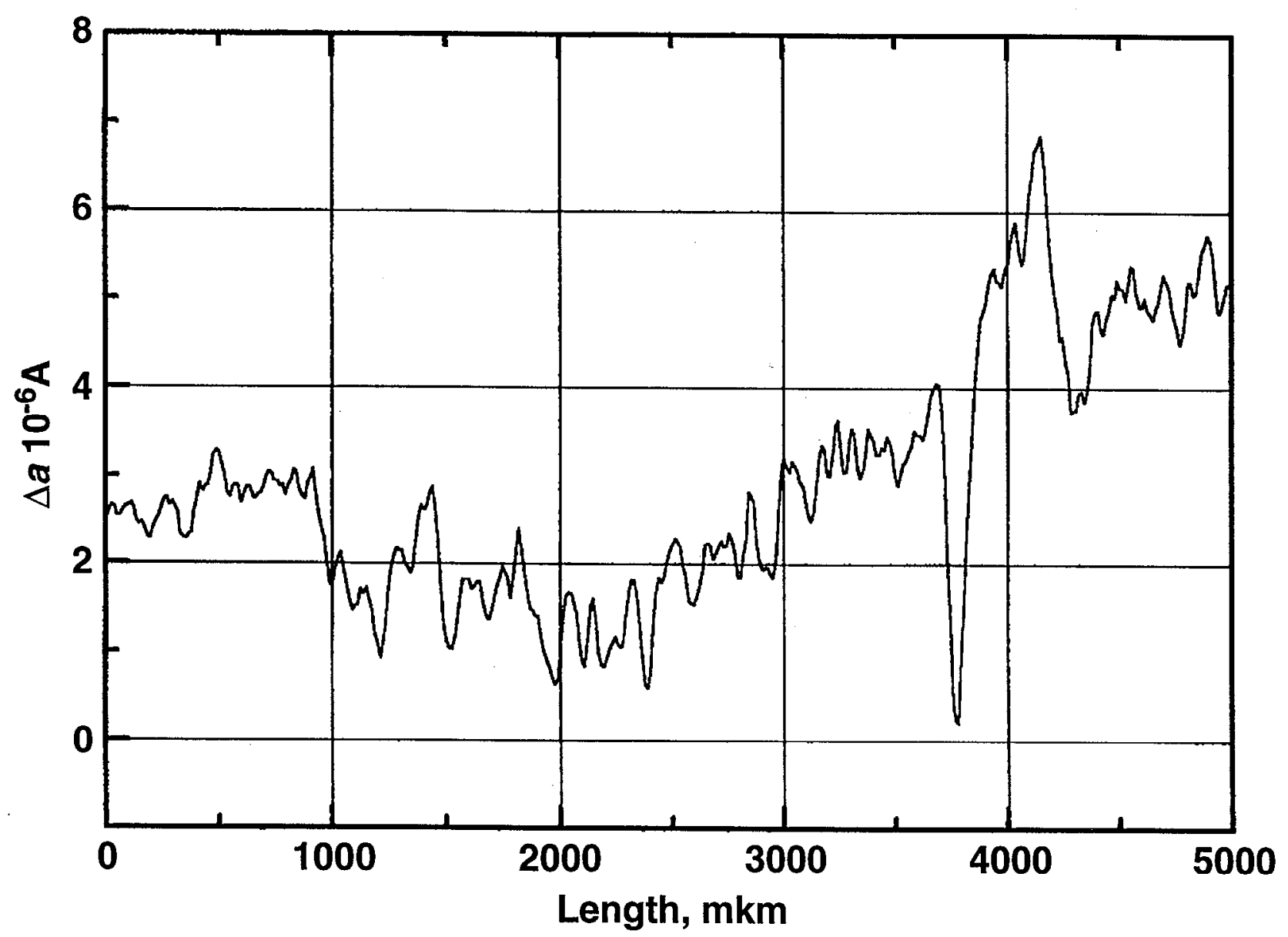

Fig. $2.4 \mathrm{c})$ 


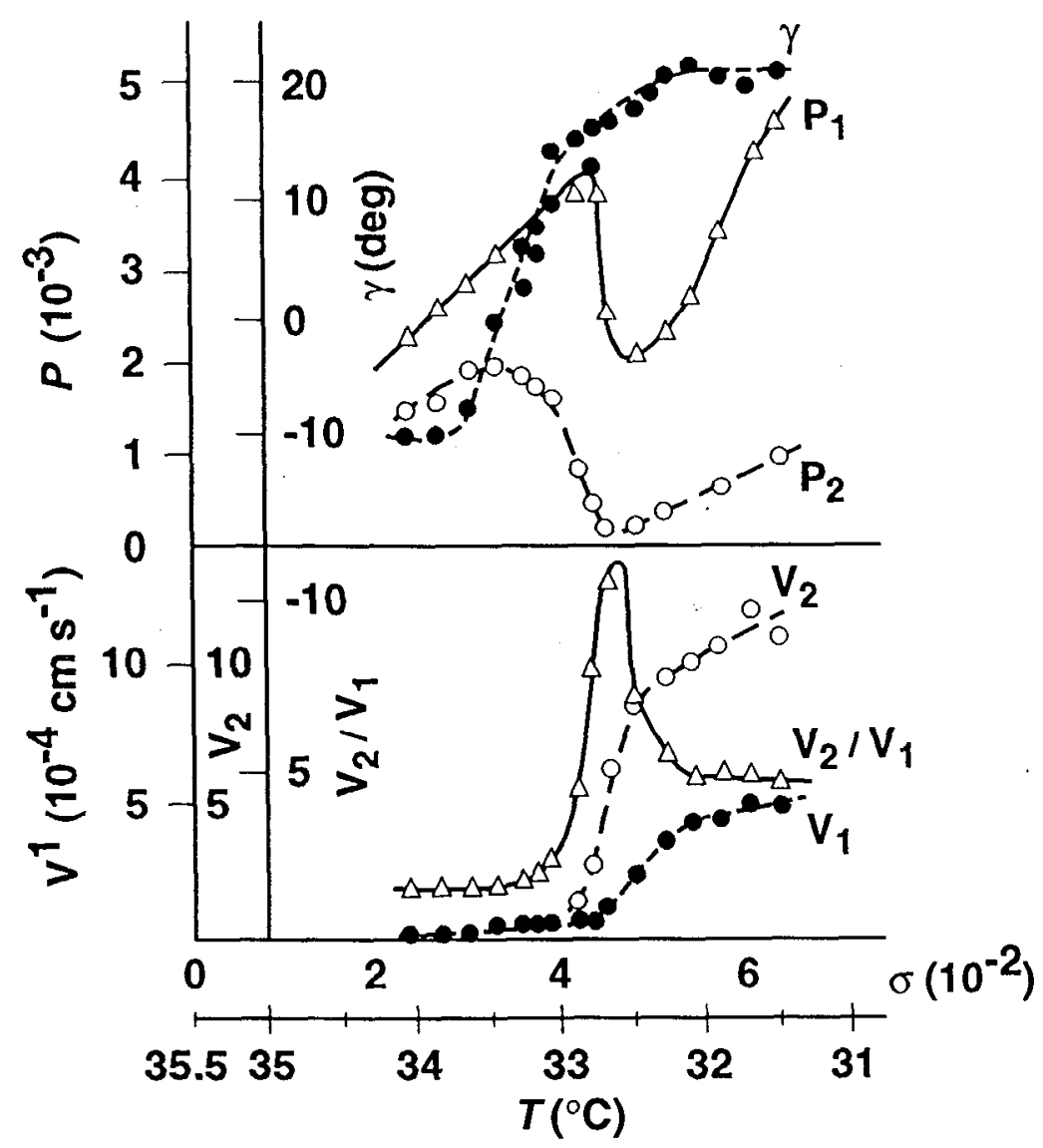

Fig. 2.5 

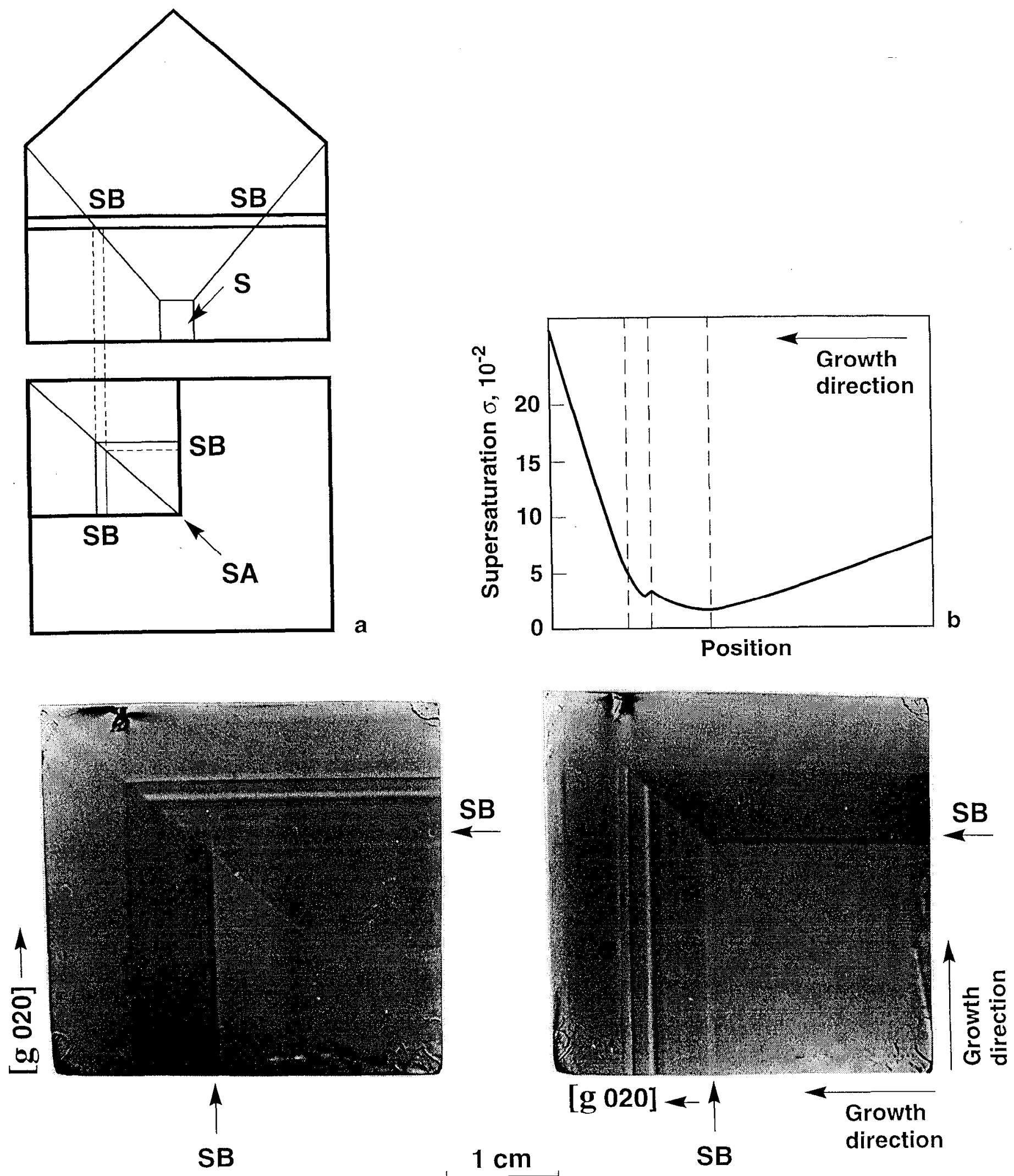

40-00-0399-0700pb01 